of the grave of a Saxon warrior of the early part of the seventh century. Its importance lies in the fact that the body had been interred with full battle equipment. A scramasceax or cutlass-knife lay across the thighs, and two knives and the remains of a spear-head were by the side. The burial is one of the few found in England which include this type of sword, commonly held to be a characteristic weapon of the Saxon tribesmen. The end of this season's work at Maiden Castle closes the fourth and final year's excavation of the site as a joint undertaking by the two societies; and the trenches are now being filled in. Excavation will, however, be continued on a small scale for some time to come.

\section{Population Policy in Germany}

WE have received, through the courtesy of Baronesse von der Goltz, two papers, written by members of the "Reichsbund der Kinderreichen" of Berlin, dealing with the present population policy of the German authorities, both Government and municipal. These papers are interesting as showing the reasoned approval of the measures taken in Germany in recent years, on the part of manyperhaps of most-Germans who have studied the legislation in question. The first paper is entitled "Birth Policy and the Problem of Space", and is written by Dr. Danzer. The author stresses the view that national existence is bound up with the question of the birth-rate, and that neglect of the obvious tendency in western Europe must lead to disaster. He thinks that the world at large is too apt to consider that Germany is over-populated and that a large population is only desired for imperialistic purposes. He points out that England and Belgium have double the population density of Germany; and he remarks that unemployment is not necessarily caused by overcrowding, as is clearly evidenced by the case of the United States. As to space, the resources of Germany are not exhausted, and the more diligent and efficient a people is, the higher the birth-rate can safely be; and, in any event, it is impossible to lay down a theoretical optimum density, which must vary with varying conditions. He makes the point that there is no instance of the decline of any country being caused by a high birth-rate. In spite of the Great War, it has been found possible to increase agricultural production, so that Germany is now nearly self-sufficient, and only has to import eggs and fats. As to the Colonies, Germany only wants these back as a source of raw materials, and not for population purposes. He ends by saying that the white race is seriously threatened, and that the day will come when every able-bodied white man, German, French, British or Italian, will be asked to save the civilization which they have built up in a millennium.

THE second paper, by Dr. Alfred Moritz, describes briefly the measures which have been taken by national socialism to relieve the economic burdens on the German family. The main purpose of these measures is the support of the financially weak.
Years ago, the Führer said that large, healthy families are the real wealth of the nation. The two-child family is mainly the result of egotism, or lack of courage to take responsibility. The policy of the "Reichsbund" is to relieve parents with at least four children. As is well known, a good deal has been done officially to encourage an increase in the birth-rate, and this policy seems to be meoting with some success. By the law of October 16, 1934, account is taken of the circumstances of those with many children. Thus, a worker with an income of 250 marks a month, with three children, pays no taxes; if unmarried he would pay 30 marks, and so on. Then there is the well-known system of wedding loans of 1,000 marks, the loan being reduced by 250 marks for each child. Then steps are being taken to provide better accommodation for large families; the houses will be provided with gardens, where this is possible. It is considered that, generally speaking, life in the big towns is unhealthy. There is a building programme for five million homes, with gardens, and easy access to the towns. Special financial help for large families is being considered in this connexion, including reduction of train fares; and much else is being done to improve the financial position of parents with large families.

\section{New Form of Saccharimeter}

THE saccharimeter, as constructed for many years, differs from the polarimeter in that it contains a system of dextro- and lævo-rotatory quartz wedges between the polarizer and analyser, the adjustment of the wedges replacing the rotation of the analyser. Monochromatic light must be used for polarimetric readings, but with the quartz wedge saccharimeter bichromate-filtered white light can be used since the rotation dispersions of quartz and carbohydrate solutions are almost the same. Until recently it has not been practicable to obtain monochromatic light of sufficient intensity and constancy for use under ordinary laboratory conditions, and the saccharimeter with white light illumination has almost universally been used for sugar analysis. A very satisfactory source of monochromatic light is now obtainable, however, in the form of an electric sodium lamp, and its introduction has led Messrs. Bellingham and Stanley, Ltd., to construct a saccharimeter, without the quartz wedge device, for use with sodium light; the instrument is identical in principle with the polarimeter and differs from the latter only in being provided with a sugar scale, reading from -30 to +110 International sugar degrees. This scale, like the angular degree scale of the polarimeter made by the same firm, is etched on a glass circle and, unlike the ordinary saccharimeter scale, requires no magnification; the Vernier attachment, also, is etched on a glass plate. The elimination of the quartz wedge system has several advantages. It obviates any error due to want of optical homogeneity of the quartz, it renders unnecessary the exact adjustment of the temperature of the apparatus to that of the observa. tion tube and the reading is taken, not by reflected, but by transmitted light. 